\title{
Apical hypertrophic cardiomyopathy in an Indian patient: straight from the book
}

\author{
Sukhvinder Singh \\ Department of Cardiology, GANESH PET CT \& Diagnostic Centre, New Delhi, India
}

Correspondence to Dr Sukhvinder Singh, kuks145@yahoo.co.in

\section{DESCRIPTION}

A 55-year-old non-hypertensive Indian man presented with a history of exertional angina. His electrocardiogram showed left ventricular hypertrophy (with biggest R-wave of $47 \mathrm{~mm}$ in V4) and giant T-wave inversion (more than $10 \mathrm{~mm}$ deep) with deepest T-wave inversion of $12 \mathrm{~mm}$ in V4 (figure 1). Echocardiogram (ECHO) showed left ventricular hypertrophy with a septal thickness of $11.7 \mathrm{~mm}$ and a posterior wall thickness of $12.2 \mathrm{~mm}$. There was striking apical hypertrophy with a thickness of $28.4 \mathrm{~mm}$ (Videos 1-3). The left ventricular cavity resembled an 'ace of spades' in diastole (figure 2). There was no evidence of left ventricular outflow tract obstruction or coarctation of the aorta.

The case has classical presentation, electrocardiographic and echocardiographic features of apical hypertrophic cardiomyopathy (HCM). An absolute apical thickness of more than $15 \mathrm{~mm}$ and a ratio of apical thickness to basal
LV wall thickness of more than 1.3 define apical HCM on ECHO. Standard ECHO may miss this entity where a contrast ECHO may be useful but cardiac MR imaging (CMR) is best. ${ }^{12}$

CMR is superior to ECHO in detecting variants of HCM such as apical HCM, presence of focal hypertrophy, severe hypertrophy $(>30 \mathrm{~mm})$ and LV apical aneurysm. Patchy mid-wall-type delayed hyperenhancement of myocardium, on contrast-enhanced CMR, identifies fibrosis. It is associated with a higher risk of adverse LV remodelling and systolic dysfunction. Its association with ventricular tachycardia has been reported but its predictive value for sudden cardiac death is not clear. ${ }^{2}$

The annual cardiovascular mortality is $\sim 0.1 \%$. New York Heart Association class II or more, age less than 41 years and presence of left atrial enlargement predict an increased incidence of myocardial infarction and atrial fibrillation. ${ }^{4}$

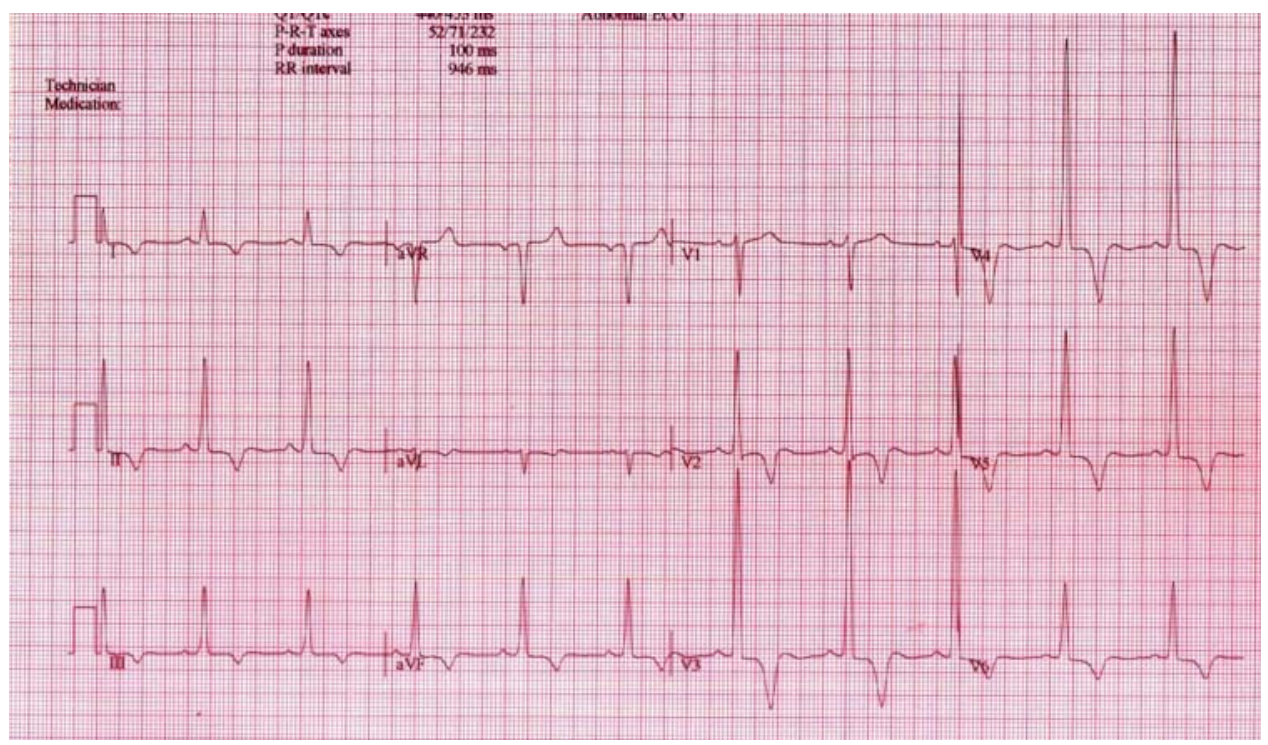

Figure 1 Electrocardiogram showing left ventricular hypertrophy with large R-wave (47 mm in V4) and giant T-wave inversion (12 mm in V4). 


\section{BMJ Case Reports}

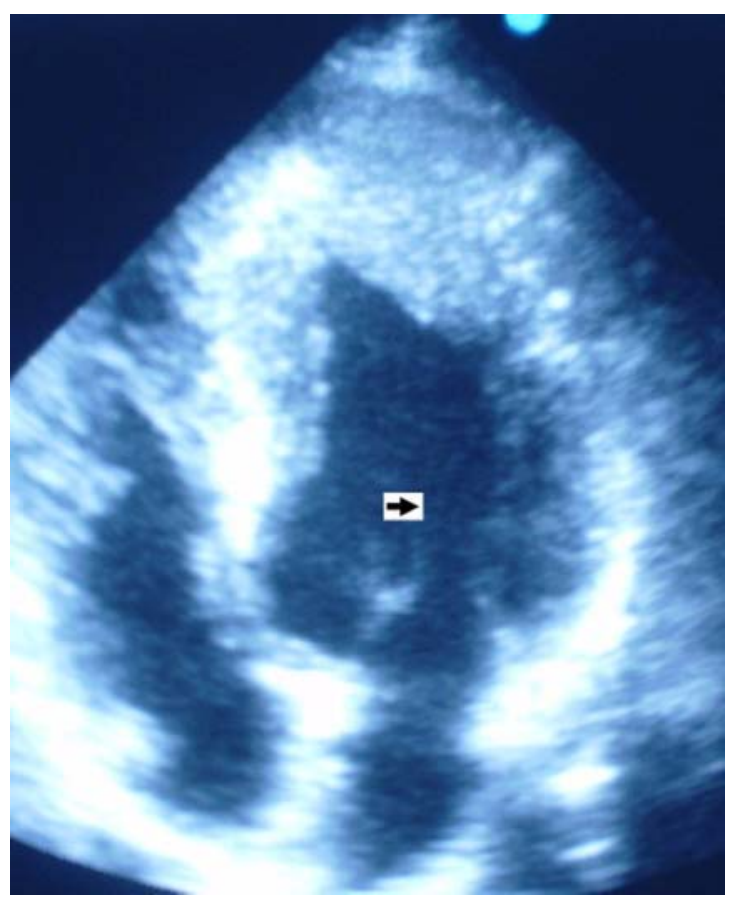

Figure 2 Apical four-chamber view of a transthoracic echocardiogram showing apical hypertrophy and an 'ace of spades'-shaped cavity (black arrow in white box) in diastole.

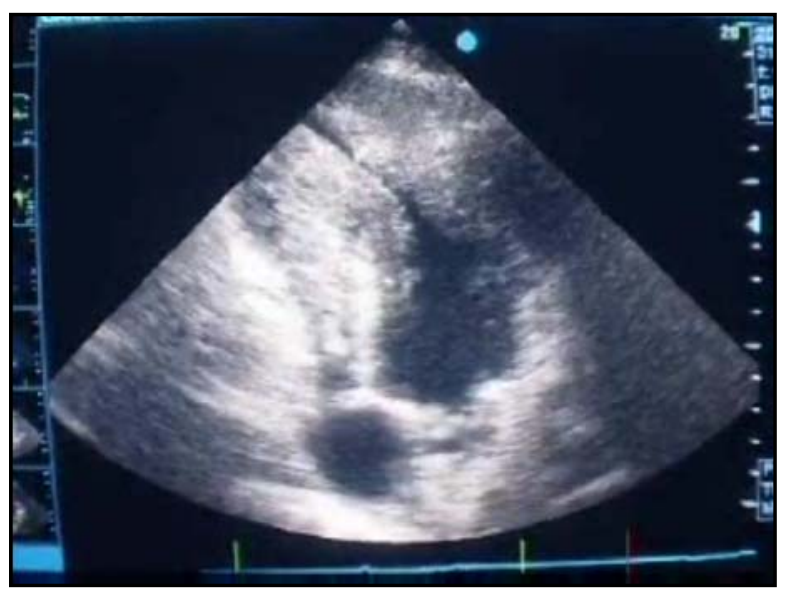

Video 1 Apical four-chamber view of a transthoracic echocardiogram showing apical hypertrophy and an 'ace of spades'-shaped cavity in diastole.

\section{Learning points}

- The case stresses that secondary causes of angina should be carefully searched for in the initial evaluation of angina before performing the stress test.

- Careful electrocardiographic and echocardiographic examination may help in identifying rare aetiologies of angina like apical hypertrophic cardiomyopathy.

- Cardiac MR imaging provides useful diagnostic and prognostic information in patients with hypertrophic cardiomyopathy.

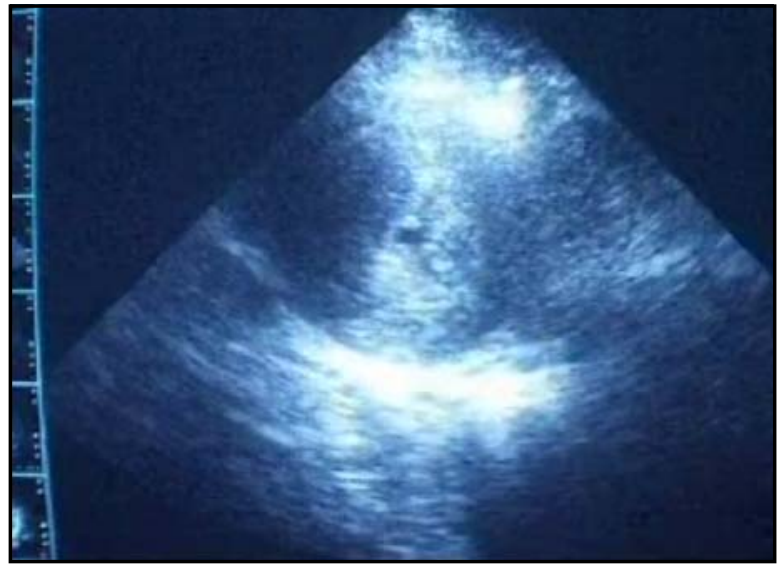

Video 2 Parasternal short axis view of a transthoracic echocardiogram showing apical hypertrophy and complete obliteration of a cavity in systole.

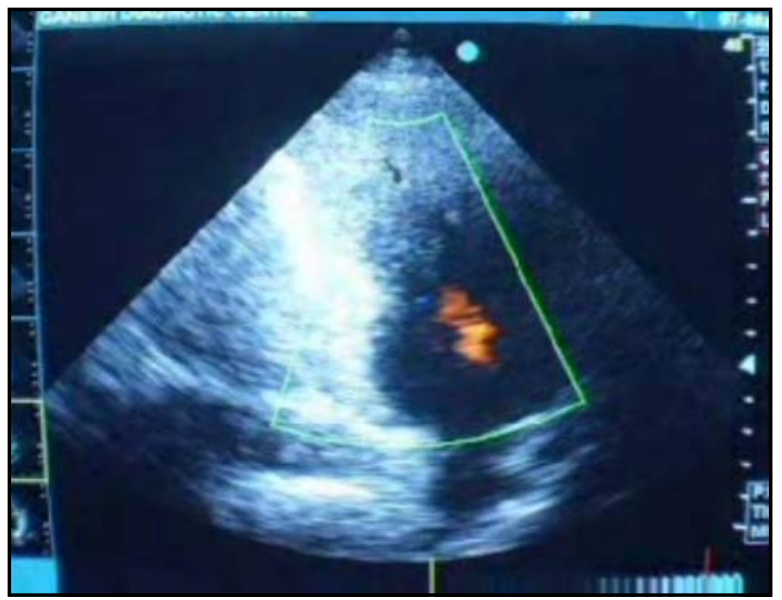

Video 3 Apical four-chamber view of a transthoracic echocardiogram with colour Doppler showing apical hypertrophy and an 'ace of spades'-shaped cavity in diastole.

\section{Competing interests None.}

Patient consent Obtained.

\section{REFERENCES}

1. Yamaguchi H, Ishimura T, Nishiyama S, et al. Hypertrophic cardiomyopathy with giant negative T waves (apical hypertrophy): ventriculographic and echocardiographic features in 30 patients. Am J Cardiol 1979;44:401-12.

2. Hansen MW, Merchant N. MRI of hypertrophic cardiomyopathy: part I, MRI appearances. AJR 2007:189:1335-43.

3. Maron MS. Clinical utility of cardiovascular magnetic resonance imaging in hypertrophic cardiomyopathy. J Cardiovasc Magn Reson 2012;14:13.

4. Eriksson MJ, Sonnenberg B, Woo A, et al. Long-term outcome in patients with apical hypertrophic cardiomyopathy. J Am Coll Cardiol 2002;39:638-45. 


\section{BMJ Case Reports}

This pdf has been created automatically from the final edited text and images.

Copyright 2012 BMJ Publishing Group. All rights reserved. For permission to reuse any of this content visit http://group.bmj.com/group/rights-licensing/permissions.

BMJ Case Report Fellows may re-use this article for personal use and teaching without any further permission.

Please cite this article as follows (you will need to access the article online to obtain the date of publication).

Singh S. Apical hypertrophic cardiomyopathy in an Indian patient: straight from the book. BMJ Case Reports 2012;10.1136/bcr-2012-006288, Published XXX

Become a Fellow of BMJ Case Reports today and you can:

- Submit as many cases as you like

- Enjoy fast sympathetic peer review and rapid publication of accepted articles

Access all the published articles

- Re-use any of the published material for personal use and teaching without further permission

For information on Institutional Fellowships contact consortiasales@bmjgroup.com

Visit casereports.bmj.com for more articles like this and to become a Fellow 